\title{
The Effects of Thyroid Hormones on Gene Expression of Acyl-Coenzyme A Thioesterases in Adipose Tissue and Liver of Mice
}

\author{
Kerstin Krause $^{\mathrm{a}}$ Juliane Weiner $^{\mathrm{a}}$ Sebastian Hönes $^{\mathrm{d}}$ Nora Klöting $^{\mathrm{a}, \mathrm{c}}$ Eddy Rijntjes ${ }^{\mathrm{e}}$ \\ John T. Heiker ${ }^{a}$ Claudia Gebhardt $^{a}$ Josef Köhrle ${ }^{e}$ Dagmar Führer $^{d}$ Karen Steinhoff $^{b}$ \\ Swen Hesse ${ }^{b, c}$ Lars C. Moeller ${ }^{d}$ Anke Tönjes ${ }^{a}$ \\ ${ }^{a}$ Division of Endocrinology and Nephrology, Department of Medicine, and bepartment of Nuclear Medicine, \\ University of Leipzig, and CIFB Adiposity Diseases, Leipzig University Medical Centre, Leipzig, d Department of \\ Endocrinology and Metabolism, University of Duisburg-Essen, Essen, and eInstitute for Experimental Endocrinology, \\ Charité-Universitätsmedizin Berlin, Berlin, Germany
}

\section{Key Words}

Thyroid hormones - Acyl-CoA thioesterases $\cdot$ Fatty acids . Brown adipose tissue

\begin{abstract}
Background: Thyroid hormones (TH) exert pleiotropic effects on glucose and lipid homeostasis. However, it is as yet unclear how $\mathrm{TH}$ regulate lipid storage and utilization in order to adapt to metabolic needs. Acyl-CoA thioesterases (ACOTs) have been proposed to play a regulatory role in the metabolism of fatty acids. Objectives: We investigated the interaction between thyroid dysfunction and Acot expression in adipose tissues and livers of thyrotoxic and hypothyroid mice. Methods: Ten-week-old female C57BL/6NTac mice ( $n=10$ /group) were made hyperthyroid by the application of L-thyroxine ( $2 \mu \mathrm{g} / \mathrm{ml}$ in drinking water) for 4 weeks. Hypothyroidism was induced in 10-week-old mice by feeding an iodine-free chow supplemented with $0.15 \%$ PTU for 4 weeks. We measured mRNA expression levels of Acot 8,11 and 13 in the liver and epididymal and inguinal white and brown adipose tissues (BAT). Furthermore, we investigated hepatic Acot gene expression in TRa- and TR $\beta$-deficient mice. Results: We showed that the expression of Acot8, 11 and 13 is
\end{abstract}

predominantly stimulated by a thyrotoxic state in the epididymal white adipose tissue. In contrast, hypothyroidism predominantly induces the expression of Acot8 in BAT in comparison with BAT of thyrotoxic and euthyroid mice $(p<$ 0.01). However, no significant changes in Acot expression were observed in inguinal white adipose tissue. In liver, Acot gene expression is collectively elicited by a thyrotoxic state. Conclusions: These data suggest that ACOTs are targets of TH and are likely to influence 3,5,3'-triiodo-L-thyronine-orchestrated mechanisms of lipid uptake, storage and utilization to adapt the regulation of metabolic demands.

\footnotetext{
(c) 2015 European Thyroid Association Published by S. Karger AG, Basel
}

\section{Introduction}

Thyroid hormones $(\mathrm{TH})$ regulate a variety of physiological processes, including growth and development, and are potent regulators of metabolism throughout life $[1,2]$. TH status correlates with body weight and energy

K.K. and J.W. contributed equally to this work.

\begin{tabular}{|c|c|}
\hline KARGER 125 & $\begin{array}{l}\text { () } 2015 \text { European Thyroid Association } \\
\text { Published by S. Karger AG, Basel }\end{array}$ \\
\hline $\begin{array}{l}\text { E-Mail karger@karger.com } \\
\text { www.karger.com/etj }\end{array}$ & $2235-0640 / 15 / 0045-0059 \$ 39.50 / 0$ \\
\hline
\end{tabular}


expenditure [3-5]. Elevated circulating concentrations of $\mathrm{TH}$ lead to a hypermetabolic state which is characterized by increased resting energy expenditure, weight loss, accelerated lipolysis and gluconeogenesis, and reduced serum cholesterol concentrations. In contrast, the manifestation of a hypothyroid state, i.e. decreased serum TH concentration, is associated with hypometabolism characterized by cold intolerance, weight gain and increased serum cholesterol concentrations [1].

It is well established that TH stimulate both a lipogenesis/lipolysis 'futile cycle' and that elevated TH concentrations lead to fat loss [6]. This is in particular regulated by the liver-specific crosstalk of the active TH 3,5,3'-triiodo-L-thyronine $\left(\mathrm{T}_{3}\right)$ by binding to its cognate receptors TR $\alpha$ and TR $\beta$ and by TR crosstalk with other nuclear receptors, for instance PPAR $\alpha$, PGC1 $\alpha$ and LXR [7]. Lipid storage and synthesis are regulated by $\mathrm{T}_{3}$ via an increased expression of lipogenic genes such as fatty acid (FA) synthase (Fas), Thrsp (Spot14) and acetyl-coA-carboxylase (Acc1) [8]. Moreover, $\mathrm{T}_{3}$ stimulates the shuttling of free FA (FFA) into mitochondria by increasing the expression and activity of CPT1 $\alpha$, which is the rate-limiting step for $\beta$-oxidation of FA in the mitochondria [9].

A prerequisite for nearly all FA metabolic pathways is the activation of ligation of FA to acyl-CoA by acyl-coA synthetases [10]. The high-energy acyl-CoA thioesters subsequently serve as substrates for numerous processes, in particular lipid synthesis and $\beta$-oxidation [11]. This process is counterbalanced by the hydrolysis of fatty acylCoA thioesters to FFA and coenzyme A (CoASH) by Acyl-CoA thioesterases (ACOTs) [12-14]. Although their reactions are well known, the cellular and metabolic effects of ACOTs are incompletely understood.

ACOTs are localized in different intracellular compartments, e.g. cytoplasm (Acot1), peroxisomes (Acot8) and in mitochondria (Acot2, 11 and 13). Acot11 is predominantly expressed in brown adipose tissue (BAT), a tissue characterized by its high number of mitochondria, in which the uncoupling of energy metabolism and ATP production by UCP-1 (uncoupling protein-1) provides the basis for nonshivering thermogenesis. In a recent study on cultured brown adipocytes it was demonstrated that there is a switch of isoform expression from $A \cot 1$ to Acot 2 during brown adipocyte differentiation, thereby shifting the availability of an intracellular pool of AcylCoA (restricted by Acot1) towards increased mitochondrial acyl-CoA uptake for $\beta$-oxidation and lipid synthesis [15]. Peroxisomal Acot8 is abundantly expressed and has a broad CoA substrate specificity. Interestingly, it has been demonstrated by Hunt et al. [16] that Acot 8 activity is inhibited by CoASH. Thus, it is anticipated that $A \cot 8$ plays a role in the regulation of intraperoxisomal $\mathrm{CoA} /$ CoASH concentrations in order to balance the availability of FA for $\beta$-oxidation [16].

In view of the unique role of ACOTs in directing lipid storage and utilization we investigated the interaction between thyroid dysfunction and Acot gene expression in adipose tissue and liver of mice. We show that gene expression of $A \cot 8,11$ and 13 is stimulated by a thyrotoxic state predominantly in epididymal white adipose tissue, whereas a hypothyroid state enhances the expression of Acot8, in particular in BAT. Likewise, hepatic Acot expression is elicited by thyrotoxicosis. These data suggest that ACOTs are targets of $\mathrm{TH}$ and may provide a fundamental means by which $\mathrm{T}_{3}$ integrates the mechanisms of lipid uptake, storage and utilization to gauge the regulation of metabolic demands.

\section{Materials and Methods}

\section{Animal Care}

Breeding and husbandry of all C57BL/6NTac mice (female, $\mathrm{n}=10$ per group) was done in the Medical Experimental Center of the University of Leipzig (Leipzig, Germany). All mice were maintained in a room under pathogen-free conditions with a controlled temperature $\left(21 \pm 1^{\circ} \mathrm{C}\right)$ on a $12 / 12 \mathrm{~h}$ light/dark cycle. Water and chow were provided ad libitum. The local ethics committee (Regierungspräsidium Leipzig) of the state of Saxony (Germany) approved the protocol of the animal experiments (approval No. TVV04/12). TR $\alpha$ - and TR $\beta$-deficient mice (male, 15 weeks old) were obtained from the European Mutant Mouse Archive [17] and the local ethics committee approved the study (Landesamt für Umwelt, Natur und Verbraucherschutz Nordrhein-Westfalen Az. 84-02.04.2014.A092).

\section{Animal Treatment}

For the induction of thyrotoxicosis, mice received L-thyroxine at a dose of $2 \mu \mathrm{g} / \mathrm{ml}$ diluted in drinking water for 4 weeks. Hypothyroidism was induced in 10-week-old mice by feeding iodinefree chow supplemented with 0.15\% PTU (catalog TD 97061; Harlan Teklan, Madison, Wis., USA) for 4 weeks. Euthyroid mice fed a normal chow diet (Altromin $\mathrm{GmbH}$, Lage, Germany) served as controls.

\section{$\mathrm{T}_{4}$ Serum Measurements}

Total $\mathrm{T}_{4}$ concentrations in serum were determined by radioimmunoassay using commercially available kits (RIA-4524; DRG Instruments $\mathrm{GmbH}$, Marburg, Germany). The samples and calibrators were incubated in duplicate with radiolabeled tracer in antibody-coated tubes according to the manufacturer's instructions. After incubation the liquid was aspirated and the antibody-bound radiolabeled tracer was counted in a gamma counter (1277 Gammamaster; LKB Wallac, Turku, Finland). The limit of quantification was $10 \mathrm{nM}$ with an intra-assay coefficient of variation of $5.5 \%$ at $36 \mathrm{nM}, 5.9 \%$ at $81 \mathrm{nM}$ and $2.2 \%$ at $169 \mathrm{nM}$.
60

Eur Thyroid J 2015;4(suppl 1):59-66 DOI: $10.1159 / 000437304$
Krause et al. 
Table 1. Primer sequences used for qPCR

\begin{tabular}{lll}
\hline Gene & Forward primer $\left(5^{\prime} \rightarrow 3^{\prime}\right)$ & Reverse primer $\left(3^{\prime} \rightarrow 5^{\prime}\right)$ \\
\hline Acots & GGTCTGGGAGATGCTCATGG & CCCAGTAATGCCTTCCTCTGT \\
A $\cot 11$ & CAGAATGTGGGCAACCACTTG & GCATGCCTCTCCGCTGAT \\
A $\operatorname{cox} 1$ & GAGTTTTGGAAAAGGTGACGCT & TGGAGCGTGCCCAGTTTAT \\
Acc 1 & TCGCAGACCCTGAAGAAATC & CCTGATTCAGCAAGGTAGGG \\
Cpt $1 \mathrm{a}$ & TACAGGATGGTTTGGCCTTT & CAAATTCTGCTGGAGAAGCC \\
Cpt2 & TGGATGGCTATGGTCAAGGT & TCTCCCTCCTTCATCAGTGG \\
Scd 1 & TGGCTGAGTGCTCCAAATACC & GCCAGATACCGTAGAGCAAACA \\
Fasn & GAGGCCTGTACGGGATCATA & CAGCCGAGCCTTGTAAGTC \\
\hline
\end{tabular}

RNA Extraction and RT-PCR

RNA was isolated from snap-frozen livers and adipose tissue using Trizol reagent (Invitrogen, Carlsbad, Calif., USA). In total, $1 \mu \mathrm{g}$ of RNA per sample was reverse transcribed in a final mixture of $5 \times$ first-strand buffer $(250 \mathrm{mM}$ Tris- $\mathrm{HCl}, \mathrm{pH} 8.3,375 \mathrm{mM} \mathrm{KCl}$, $15 \mathrm{mM} \mathrm{MgCl}_{2}$ ), $0.5 \mathrm{~mm}$ of dNTPs, $5 \mathrm{mM}$ of DTT (Promega, Madison, Wis., USA), 15 U of Prime RNase Inhibitor (ThermoFisher, Waltham, Mass., USA), $0.5 \mu \mathrm{g}$ of random hexamer primers and $200 \mathrm{U}$ of Moloney murine leukemia virus reverse transcriptase (Promega). Reverse transcription was performed at $37^{\circ} \mathrm{C}$ for 60 $\min$ and $94^{\circ} \mathrm{C}$ for $5 \mathrm{~min}$.

\section{Quantitative Real-Time PCR}

Exon/intron spanning primers were designed to quantitatively calculate the expression of the Acot8, 11 and 13 isoforms in mouse liver and adipose tissue. The primer sequences are presented in table 1. Gene expression was analyzed in duplicate by reverse-transcriptase real-time PCR by using the commercial LightCyclerDNA Master SYBR Green I Kit (Roche, Mannheim, Germany) as previously described [18]. Gene expression was analyzed according to the $\Delta \Delta \mathrm{Ct}$ method normalized to housekeeping genes $36 B 4$ (adipose tissue) or $18 \mathrm{~s}$ (liver), and expression levels were calculated as $2^{-\Delta \Delta \mathrm{Ct}}[19]$. Data are expressed as the mean \pm SEM. All statistical analyses and final presentations were performed using GraphPad Prism 6.0 software (GraphPad, San Diego, Calif., USA). One-way ANOVA followed by the Bonferroni's post hoc test was used for multiple comparisons between groups. $\mathrm{p}$ values $\leq 0.05$ were considered to be significant.

Histology and Oil Red O Staining

For oil red $\mathrm{O}$ staining, livers were shock frozen in liquid nitrogen, embedded in OCT cryostat sectioning medium (Fisher Scientific, Schwerte, Germany) and cut at $8 \mu \mathrm{m}$. Sections were subjected to oil red $\mathrm{O}$ staining as described and counterstained with hematoxylin [20].

\section{Results}

Characterization of Thyrotoxic and Hypothyroid Mice Thyroid dysfunction was established as described in Materials and Methods. Hypothyroid female mice had significantly reduced $\mathrm{T}_{4}$ concentrations $(14.00 \pm 1.2 \mathrm{nM})$ compared to thyrotoxic $(41.33 \pm 3.67 \mathrm{nM}, \mathrm{p}<0.01)$ and euthyroid mice ( $37.5 \pm 0.5 \mathrm{~nm}, \mathrm{p}<0.001$; fig. 1a).

In liver, the expression of genes known to be TH responsive, Dio 1 and $P d k 4$, were significantly downregulated in hypothyroid mice and upregulated in thyrotoxic mice compared to euthyroid controls (fig. 1b). Thyroxinbinding globulin, $\mathrm{Tbg}$, was studied as an example of a hepatic gene that is negatively regulated by $\mathrm{TH}$. There was a 12-fold increase in Tbg mRNA expression in hypothyroid mice (fig. 1b). Altogether, in addition to the $\mathrm{T}_{4}$ serum concentration, the gene expression analysis of TH-responsive genes further confirms the thyrotoxic and hypothyroid phenotype of the $\mathrm{T}_{4}$ - and PTU-treated mouse cohorts.

\section{Distinct Tissue-Specific Acot Gene Expression in Mice} with Thyroid Dysfunction

To address the impact of thyroid dysfunction on Acot gene expression in major tissues relevant for lipid metabolism, we first investigated Acot gene expression in epididymal (eWAT) and inguinal (iWAT) white adipose tissue and interscapular BAT in thyrotoxic, hypo- and euthyroid mice. Interestingly, we found both (i) fat depot-specific differences in the expression of Acot and (ii) a switch of Acot expression associated with thyroid status (fig. 2). The Acot11 gene reached the significantly highest values in white fat depots, eWAT and inguinal iWAT of thyrotoxic mice (fig. 2a). There was a 6-fold increase in eWAT in these mice when compared to eWATs of hypothyroid and euthyroid mice ( $p<0.001$; fig. $2 \mathrm{a}$ ). The same regulation was found for Acot13, with predominant expression in eWAT of thyrotoxic mice with a 5-fold higher expression compared to eWATs of hypothyroid and euthyroid mice ( $p<0.001$, respectively; fig. 2b). Similarly, Acot8 was overexpressed in the eWAT of thyrotoxic mice. However, in a hypothyroid state Acot8 expression was highest in the 


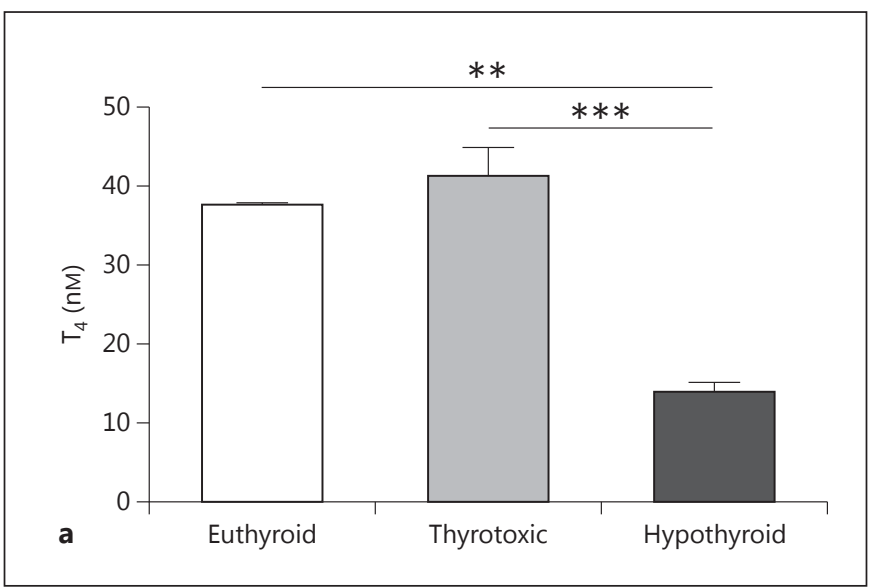

Fig. 1. Characterization of thyrotoxic and hypothyroid mice. Serum $\mathrm{T}_{4}$-concentrations in thyrotoxic, hypothyroid and euthyroid female mice (a) and mRNA expression of TH responsive genes in liver (b) confirm the thyrotoxic and hypothyroid phenotype of

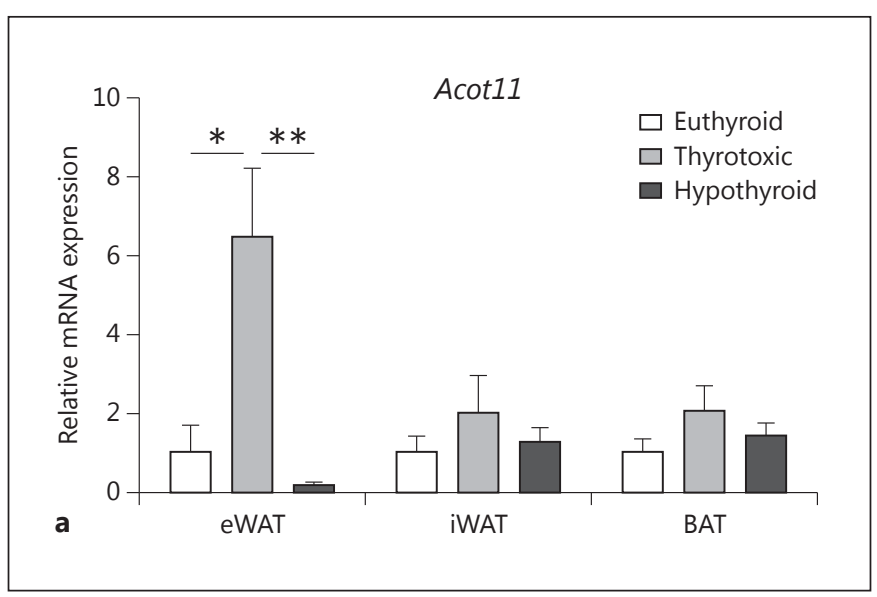

Fig. 2. Effect of altered TH status on Acot gene expression in adipose tissue. The mRNA expression of $A \cot 11$ (a), $A \cot 13$ (b) and $A \cot 8$ (c) genes was determined in WAT (eWAT, iWAT) and BAT of thyrotoxic, hypothyroid and euthyroid female mice. Statistical analysis was performed by one-way ANOVA followed by Bonferroni's post hoc test. Data are presented as means \pm SEM. ${ }^{*} \mathrm{p}<0.05,{ }^{* *} \mathrm{p}<0.01,{ }^{* * *} \mathrm{p}<0.001$.

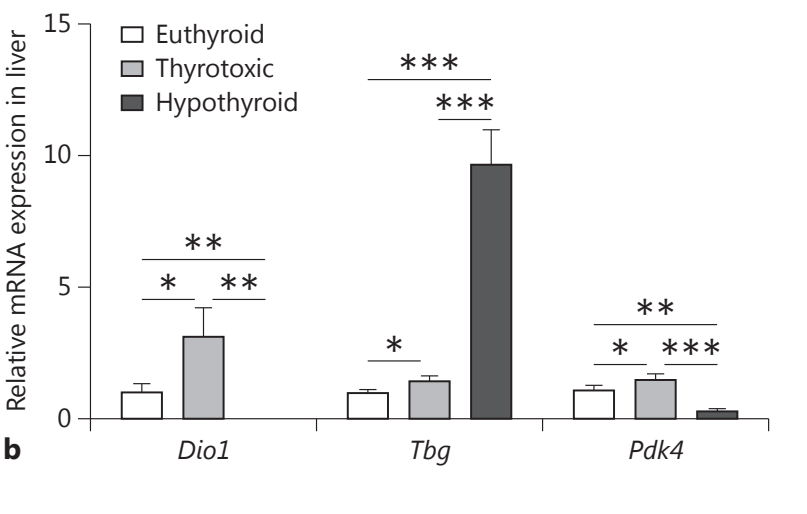

the $\mathrm{T}_{4^{-}}$and PTU-treated mouse cohorts. Statistical analysis was performed by one-way ANOVA followed by Bonferroni's post hoc test. Data are presented as means \pm SEM. ${ }^{*} \mathrm{p}<0.05$, ** $\mathrm{p}<0.01,{ }^{* * *} \mathrm{p}<0.001$.
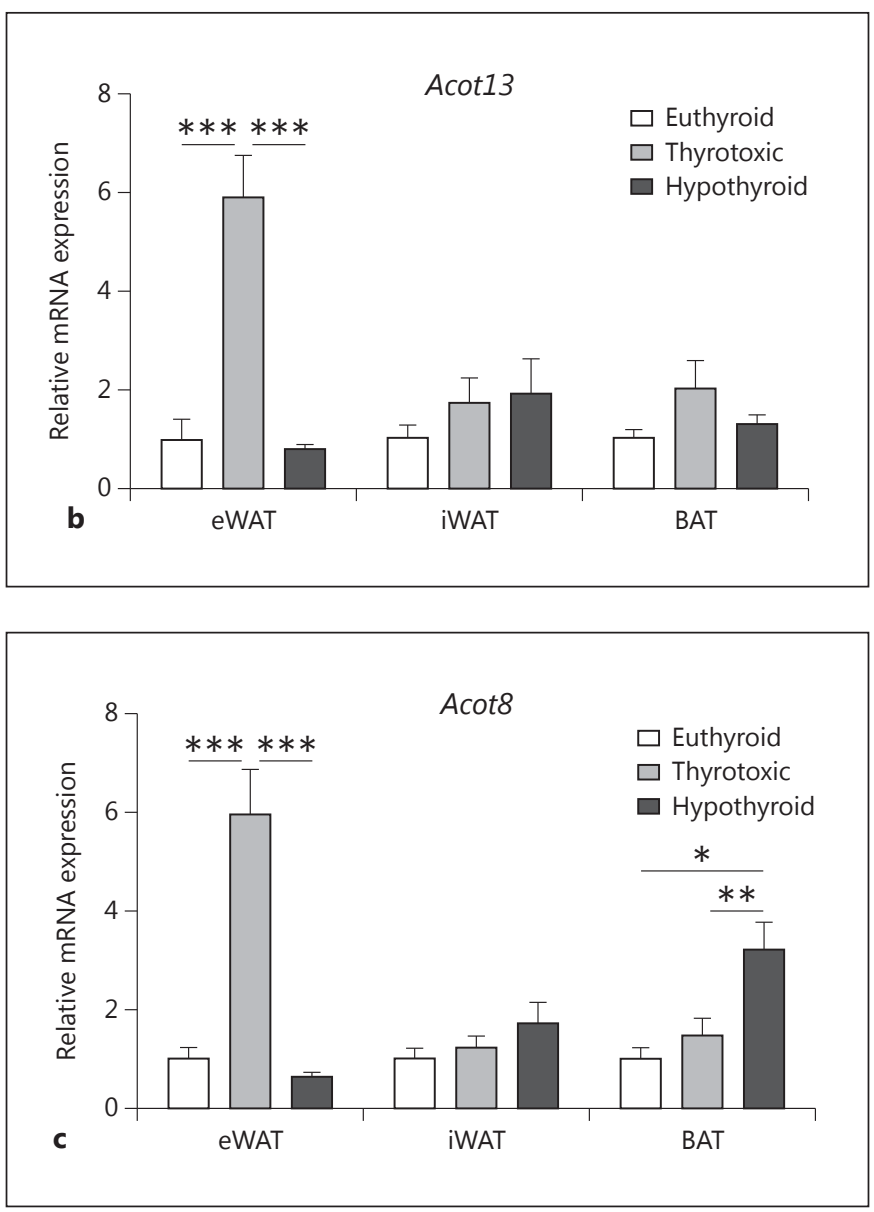

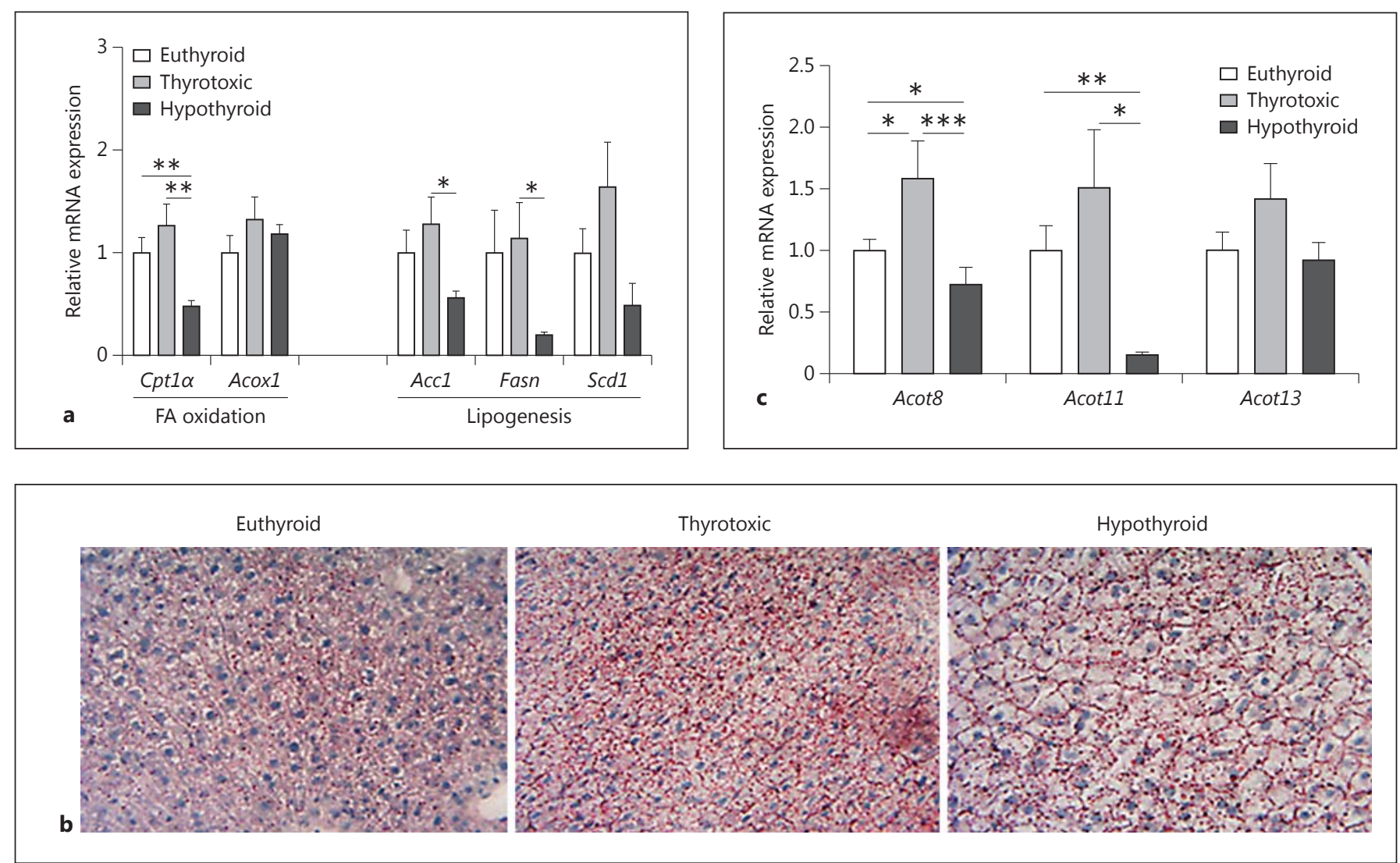

Fig. 3. Effect of altered $\mathrm{TH}$ status on liver lipid metabolism. a Quantitative RT-PCR of genes involved in FA oxidation and lipogenesis. Euthyroid values were defined as 1 and changes in thyrotoxic and hypothyroid animals were expressed as relative amounts compared with euthyroid controls ( $\mathrm{n}=5$ per group). b Representative oil red $\mathrm{O}$ stainings and hematoxylin stainings in euthyroid, thyrotoxic and hypothyroid mice ( $n=5$ per group). c Gene expression of Acot8, 11 and 13 analyzed in livers of thyrotoxic, hypothyroid and euthyroid mice. Statistical analysis was performed by one-way ANOVA followed by Bonferroni's post hoc test. Data are presented as means \pm SEM. ${ }^{*} \mathrm{p}<0.05,{ }^{* *} \mathrm{p}<0.01$, $* * * \mathrm{p}<0.001$.
BAT, which was 3-fold higher compared to Acot8 expression in the BAT of thyrotoxic and euthyroid mice (p < 0.01; fig. 2c). Collectively, the data suggest that gene expression of $A \cot 8,11$ and 13 are stimulated by a thyrotoxic state predominantly in eWAT, whereas low TH concentrations elevate expression of the Acot8 isoform in BAT.

\section{Increased Hepatic Acot Gene Expression in Thyrotoxic} Mice

In order to elucidate a potential role of $\mathrm{TH}$-induced Acot expression on hepatic lipid metabolism, we first examined the mRNA expression of genes associated with lipid metabolism in livers of thyrotoxic or hypo- and euthyroid female mice (fig. 3). In the livers of hypothyroid mice, expression of genes involved in FA oxidation as well as lipogenic genes is decreased ( $p<0.001$ for $C p t 1 \alpha$ and $\mathrm{p}<0.05$ for Scd1; fig. 3a). Although these genes encode for proteins which promote or reduce hepatic triglyceride content, no triglyceride accumulation in the liver was observed in the thyrotoxic, hypo- or euthyroid mice (fig. 3b). Similar to the observed increase in transcript concentrations of Acot in eWAT in a thyrotoxic state, in livers of thyrotoxic mice a trend towards collective upregulation of all analyzed Acot transcripts was evident when compared to the livers of hypothyroid and euthyroid mice (fig. 3c). Collectively, these data suggest the induction of hepatic Acot gene expression by TH.

\section{Hepatic Acot Expression in TR $\alpha$ and TR $\beta$ Knockout Mice}

In liver, $\mathrm{T}_{3}$ exerts its effects on lipid and carbohydrate metabolism by binding to its cognate nuclear receptors 
TR $\alpha$ and TR $\beta$. Prolonged treatment with $\mathrm{T}_{3}$ promotes FA catabolism [6]. Having shown that expression of ACOTs is coordinately upregulated by $\mathrm{TH}$ in livers in vivo, we next aimed to assess whether this effect is mediated by TR. We used male TR $\alpha$ and TR $\beta$ knockout (KO) mice and compared the hepatic Acot gene expression to that in wild-type mice. As shown in figure 4, deficiency of TRa had no effect on hepatic Acot expression. However, in livers of TR $\beta$-deficient mice there was a significant upregulation of Acot 8 compared to the wild-type mice (1.5-fold, $\mathrm{p}<0.05)$. This effect was even stronger for Acot 11 with a 5 -fold increase in TR $\beta$-deficient mice versus wild-type controls ( $\mathrm{p}<0.05$; fig. 4$)$. The highly elevated serum and liver TH concentrations in TR $\beta$-deficient mice $[8,21]$ possibly increase the hepatic expression of $A \cot 8$ and 11 via compensation by TRa. It therefore appears as if both TRs can mediate Acot expression in liver, at least for Acot8 and 11.

\section{Discussion}

TH influence a wide variety of physiological processes, including growth and differentiation as well as thermogenesis. To date little is known about the molecular mechanisms by which TH orchestrates energy storage and expenditure within the cell. Lipogenesis as well as lipolysis are regulated by $\mathrm{T}_{3}$, and it is well known that $\mathrm{T}_{3}$ stimulates the shuttling of FFA into mitochondria [22]. In recent years, a number of ACOTs have been identified with distinct roles in lipid metabolism. It has been demonstrated that Acot11 is upregulated in BAT when mice are exposed to cold and it has been proposed that Acot11 supports the transition of this tissue towards increased metabolic activity, most likely through alteration of intracellular fatty acyl-CoA concentration [23]. In our present work we found a significant upregulation of $A \cot 11$ in eWAT from thyrotoxic mice but not in BAT. Depot-specific differences in adipose tissue lipolysis are well known, for instance in the context of FFA release from the adipocyte. As an example, visceral (omental) cultured differentiated preadipocytes display a greater FFA flux than subcutaneous adipocytes, suggesting the contribution of a partially cell-autonomous mechanism [24]. Whether or not visceral Acot11 expression in thyrotoxic mice represents such a regulatory point in visceral FA metabolism by balancing lipid storage and FA oxidation needs to be addressed in further functional studies.

A second finding of the present work was that the lack of TH triggers Acot8 expression in BAT. Acot8 is a per-

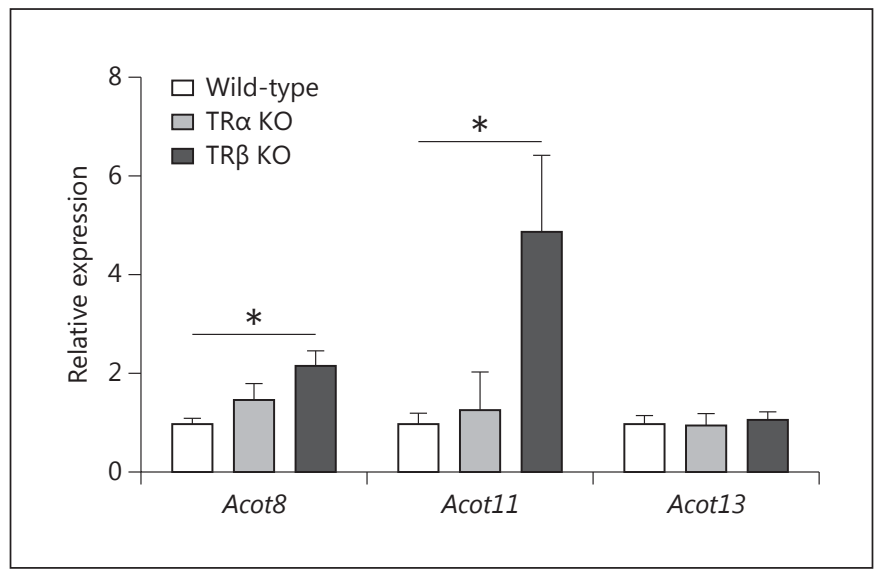

Fig. 4. Effect of TR KO on hepatic Acot expression. Gene expression of $A \cot 8,11$ and 13 analyzed in livers of TR $\alpha$ or TR $\beta$ KO mice and wild-types under euthyroid conditions. Wild-type values were defined as 1 and changes in TR $\alpha$ and TR $\beta$ KO mice were expressed as relative amounts compared with the euthyroid wild-type controls ( $\mathrm{n}=5$ per group). Statistical analysis was performed by oneway ANOVA followed by Bonferroni's post hoc test. Data are presented as means \pm SEM. ${ }^{*} \mathrm{p}<0.05$.

oxisomal ACOT whose activity is strongly inhibited by $\mathrm{CoASH}$, suggesting a role of $A \cot 8$ in the regulation of peroxisomal $\mathrm{CoA} / \mathrm{CoASH}$ concentrations. Peroxisomes optimize the flux of FA through $\beta$-oxidation and also participate in the synthesis of bile acids [14, 25]. It is worth noting that bile acids stimulate deiodinase 2 activity in $\mathrm{BAT}$, thereby promoting energy expenditure and preventing resistance to insulin and obesity [26]. However, the contribution of Acot 8 in the circuit of bile acids/ cAMP/deiodinase 2 in BAT is thus far elusive. Additionally, it has been demonstrated that in BAT Dio2 may regulate the local availability of $\mathrm{T}_{3}$. This results not only in an increase of the intracellular but also the extracellular $\mathrm{T}_{3}$ pool [27-30]. In fact, $30-40 \%$ of $\mathrm{T}_{3}$ is produced by PTU-insensitive pathways in adult athyroid $\mathrm{T}_{4}$-supplemented [29], cold-exposed [28], preweaning [31] or hypothyroid rats $[29,30]$. Since Dio2 is insensitive to PTU [29], it is likely that the compensatory local BAT $\mathrm{T}_{3}$ concentration contributes to enhanced Acot 8 gene expression in hypothyroid BAT.

TH regulation of lipid metabolism in liver is primarily dependent on direct actions of $\mathrm{T}_{3}$ on TR as well as indirect crosstalks with nutrient-activated nuclear receptors, such as PPAR $\alpha$ and LXR. LXR and TR $\beta$ control the expression of key enzymes involved in FA oxidation as well as lipogenesis, such as Cpt1 $\alpha$, Fasn and Acc1 [1]. In the livers of our hypothyroid mice these enzymes were
Krause et al. 
decreased, but were upregulated in thyrotoxic mice (fig. 2a). There were no differences in hepatic lipid stores between thyrotoxic and hypothyroid animals, as indicated by oil red $\mathrm{O}$ staining (fig. 2b). However, expression of Acot8, 11 and 13 were significantly higher in thyrotoxic compared to livers of hypothyroid mice (fig. $2 \mathrm{c}$ ). In view of the upregulation of genes involved in $\beta$-oxidation, the overexpression of ACOT might represent a regulatory trait in hepatic FA metabolism by limiting the access of acyl-CoA thioesters to FA oxidation. Genetic inactivation of TRa does not alter hepatic Acot expression compared to wild-type mice. However, elevated transcript concentrations of both $A \cot 8$ and 11, but not $A \cot 13$, in TR $\beta$ KO mice compared to wild-type livers suggest a TR $\beta$-independent stimulation of gene expression. This might be related to nonclassical effects of TH known to be markedly elevated in the serum and livers of TH-resistant TR $\beta$ mice $[8,21]$. Alternatively, both hepatic $A \cot 8$ and 11, but not $A \cot 13$, gene expression might be regulated indirectly by yet unidentified hepatic and/or systemic factors, hormones or metabolites altered in TR $\beta$-deficient TH-resistant mice. For instance, in mice with TR mutations crosstalks between TH and PPAR $\alpha$ [32] as well as LXR [33] have been demonstrated.
In summary, our study provides the first evidence that ACOTs are targets of $\mathrm{TH}$ and that a disturbed $\mathrm{TH}$ status is associated with alterations in Acot gene expression in the liver and both white and brown fat depots in mice. In the liver the changes in Acot expression are not primarily dependent on the direct actions of TH on TR. However, our observations may add to the knowledge of TH-regulated hepatic lipid metabolism. Finally, the finding of increased expression of Acot8 in the BAT of hypothyroid mice might provide further insight into the oxidative metabolism in BAT under TH-deprived conditions.

\section{Acknowledgement}

This work was supported by grants from the German Research Council (DFG Priority Programme 1629 and SFB 1052 'obesity mechanisms' C01, C07, B4), from the German Diabetes Association and from the DHFD (Diabetes Hilfs- und Forschungsfonds Deutschland).

\section{Disclosure Statement}

The authors have nothing to disclose.

\section{References}

1 Brent GA: Mechanisms of thyroid hormone action. J Clin Invest 2012;122:3035-3043.

2 McAninch EA, Bianco AC: Thyroid hormone signaling in energy homeostasis and energy metabolism. Ann NY Acad Sci 2014;1311:7787.

3 Iwen KA, Schröder E, Brabant G: Thyroid hormones and the metabolic syndrome. Eur Thyroid J 2013;2:83-92.

-4 Jourdan C, Linseisen J, Meisinger C, Petersen A-K, Gieger C, Rawal R, et al: Associations between thyroid hormones and serum metabolite profiles in an euthyroid population. Metabolomics 2014;10:152-164.

5 Vergani L: Lipid lowering effects of iodothyronines: in vivo and in vitro studies on rat liver. World J Hepatol 2014;6:169-177.

6 Oppenheimer JH, Schwartz HL, Lane JT, Thompson MP: Functional relationship of thyroid hormone-induced lipogenesis, lipolysis, and thermogenesis in the rat. J Clin Invest 1991;87:125-132.

-7 Coppola M, Glinni D, Moreno M, Cioffi F, Silvestri E, Goglia F: Thyroid hormone analogues and derivatives: actions in fatty liver. World J Hepatol 2014;6:114-129.
8 Flores-Morales A, Gullberg H, Fernandez L, Ståhlberg N, Lee NH, Vennström B, et al: Patterns of liver gene expression governed by TR $\beta$. Mol Endocrinol 2002;16:1257-1268.

>9 Jackson-Hayes L, Song S, Lavrentyev EN, Jansen MS, Hillgartner FB, Tian L, et al: A thyroid hormone response unit formed between the promoter and first intron of the carnitine palmitoyltransferase-Ia gene mediates the liver-specific induction by thyroid hormone. J Biol Chem 2003;278:7964-7972.

10 Watkins PA, Ellis JM: Peroxisomal acyl-CoA synthetases. Biochim Biophys Acta 2012; 1822:1411-1420.

11 Watkins PA: Fatty acid activation. Prog Lipid Res 1997;36:55-83.

12 Cohen DE: New players on the metabolic stage. Adipocyte 2013;2:3-6.

13 Li LO, Klett EL, Coleman RA: Acyl-CoA synthesis, lipid metabolism and lipotoxicity. Biochim Biophys Acta 2010;1801:246-251.

14 Hunt MC, Alexson SEH: The role Acyl-CoA thioesterases play in mediating intracellular lipid metabolism. Prog Lipid Res 2002;41:99130.
15 Momose A, Fujita M, Ohtomo T, Umemoto N, Tanonaka K, Toyoda H, et al: Regulated expression of acyl-CoA thioesterases in the differentiation of cultured rat brown adipocytes. Biochem Biophys Res Commun 2011; 404:74-78.

16 Hunt MC, Solaas K, Kase BF, Alexson SEH: Characterization of an Acyl-CoA thioesterase that functions as a major regulator of peroxisomal lipid metabolism. J Biol Chem 2002; 277:1128-1138.

17 Gauthier K, Chassande O, Plateroti M, Roux JP, Legrand C, Pain B, et al: Different functions for the thyroid hormone receptors TRa and TR $\beta$ in the control of thyroid hormone production and post-natal development. EMBO J 1999;18:623-631.

18 Krause K, Eszlinger M, Gimm O, Karger S, Engelhardt C, Dralle H, et al: TFF3-based candidate gene discrimination of benign and malignant thyroid tumors in a region with borderline iodine deficiency. J Clin Endocrinol Metab 2008;93:1390-1393.

19 Livak KJ, Schmittgen TD: Analysis of relative gene expression data using real-time quantitative PCR and the $2^{-\Delta \Delta \mathrm{C}_{\mathrm{T}}}$ method. Methods 2001;25:402-408. 
20 Ruschke K, Illes M, Kern M, Klöting I, Fasshauer M, Schön MR, et al: Repin1 maybe involved in the regulation of cell size and glucose transport in adipocytes. Biochem Biophys Res Commun 2010;400:246-251.

21 Flamant F, Samarut J: Thyroid hormone receptors: lessons from knockout and knock-in mutant mice. Trends Endocrinol Metab 2003; 14:85-90.

22 Elks ML, Manganiello VC: Effects of thyroid hormone on regulation of lipolysis and adenosine $3^{\prime}, 5^{\prime}$-monophosphate metabolism in 3T3-L1 adipocytes. Endocrinology 1985;117: 947-953.

-23 Adams SH, Chui C, Schilbach SL, Yu XX, Goddard AD, Grimaldi JC, et al: BFIT, a unique acyl-CoA thioesterase induced in thermogenic brown adipose tissue: cloning, organization of the human gene and assessment of a potential link to obesity. Biochem J 2001;360:135-142.

-24 Caserta F, Tchkonia T, Civelek VN, Prentki M, Brown NF, McGarry JD, et al: Fat depot origin affects fatty acid handling in cultured rat and human preadipocytes. Am J Physiol Endocrinol Metab 2001;280:E238E247.
25 Wanders RJA, Waterham HR: Peroxisomal disorders: the single peroxisomal enzyme deficiencies. Biochim Biophys Acta 2006;1763: 1707-1720.

26 Watanabe M, Houten SM, Mataki C, Christoffolete MA, Kim BW, Sato H, et al: Bile acids induce energy expenditure by promoting intracellular thyroid hormone activation. $\mathrm{Na}$ ture 2006;439:484-489.

27 Silva JE, Gordon MB, Crantz FR, Leonard JL, Larsen PR: Qualitative and quantitative differences in the pathways of extrathyroidal triiodothyronine generation between euthyroid and hypothyroid rats. J Clin Invest 1984;73: 898-907.

28 Silva JE, Larsen PR: Potential of brown adipose tissue type II thyroxine $5^{\prime}$-deiodinase as a local and systemic source of triiodothyronine in rats. J Clin Invest 1985;76:2296-2305.

29 Silva JE, Leonard JL, Crantz FR, Larsen PR: Evidence for two tissue-specific pathways for in vivo thyroxine $5^{\prime}$-deiodination in the rat. J Clin Invest 1982;69:1176-1184.
30 Christoffolete MA, Linardi CCG, Jesus L de, Ebina KN, Carvalho SD, Ribeiro MO, et al: Mice with targeted disruption of the Dio2 gene have cold-induced overexpression of the Uncoupling Protein 1 gene but fail to increase brown adipose tissue lipogenesis and adaptive thermogenesis. Diabetes 2004;53:577-584.

31 Silva JE, Matthews P: Thyroid hormone metabolism and the source of plasma triiodothyronine in 2-week-old rats: effects of thyroid status. Endocrinology 1984;114:2394-2405.

32 Liu Y-Y, Heymann RS, Moatamed F, Schultz JJ, Sobel D, Brent GA: A mutant thyroid hormone receptor alpha antagonizes peroxisome proliferator-activated receptor alpha signaling in vivo and impairs fatty acid oxidation. Endocrinology 2007;148:1206-1217.

33 Hashimoto K, Cohen RN, Yamada M, Markan KR, Monden T, Satoh T, et al: Cross-talk between thyroid hormone receptor and liver $\mathrm{X}$ receptor regulatory pathways is revealed in a thyroid hormone resistance mouse model. J Biol Chem 2006;281:295-302. 